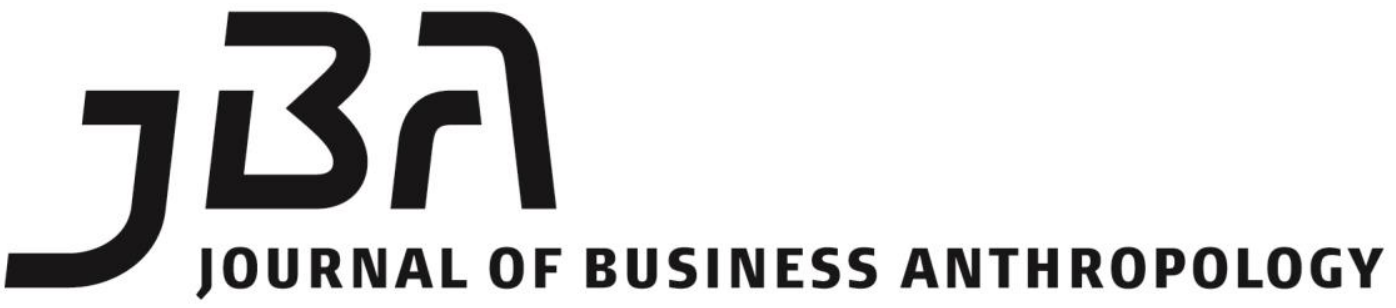

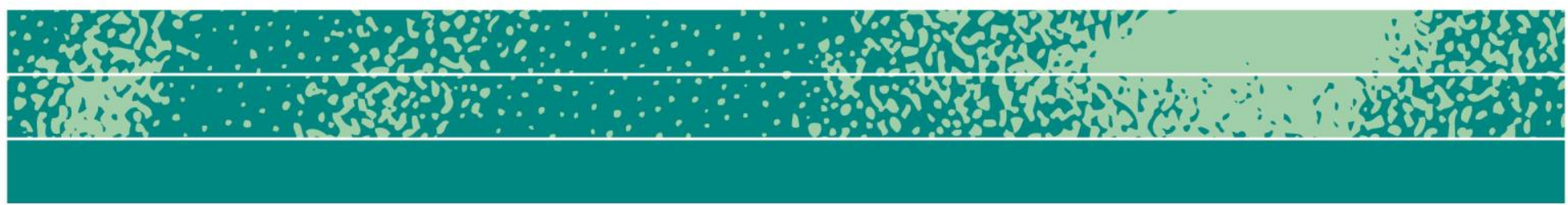

\section{Homes and Paths: Notes on Finding Place in Consumer Anthropology}

Kevin Browne

\begin{abstract}
Homes are often the site of research in business anthropology. The relatively brief time frames of much consumer research can lead to a perception of stability of space-time rather than one of indeterminacy and flux. In this article I explore examples of such flows in the home and how they are actively produced. Following Latour, Ingold, and other theorists, I examine the co-creation of "home" by human and non-human actors in order to destabilize the concept and to open our research to richer possibilities and greater habitability.
\end{abstract}

\section{Keywords}

Home; Paths; Flux; Identity; Place
Page 1 of 17

JBA 3(1): 109-125 Spring 2014

(C) The Author(s) 2014

ISSN 2245-4217

www.cbs.dk/jba 
"Even more troubling than the lack of space is the lack of place."

Bruno Latour (2009: 144)

"This is our upstairs garage. It's supposed to be our master bedroom but we use it for storage... [Fixing it up] isn't a high motivation because we like our current bedroom. There are always higher priorities for time and money...It's a source of frustration."

Jack (research participant)

\section{Theorizing the home}

I start with an idea that may seem in some ways obvious and in others a provocation: not only is the home unstable, both conceptually and materially, but it might be more accurately viewed as a temporary rest stop along a path. As ethnographers and designers working in industry, we are often circumscribed by significant time and related constraints. Unfortunately, these exigencies can sometimes lead to a collapsing of time and a freezing of space, the result of which is we may assign stability and structure rather than perceiving indeterminacy and movement.

Because many of us working in business and design anthropology often conduct research in people's homes, we need to understand how such places are embodied as sites of generativity, flux, contestation, and identity. Despite the seeming stability and solidity granted by modernist theories of architecture and domesticity, all homes betray cracks and indeterminacies (Massey 2005: 116.); they inevitably leak. My goal is to seek some practical ways to more productively theorize the home in our work. I will draw on research I did on understanding the home in the Midwestern U.S., and engage these data with the theories of Bruno Latour, Tim Ingold, Nancy Munn, and others. Specifically, I foreground the idea of flux, and engage with Latour's recent idea of compositions as a way of relocalizing the global, Ingold's work on understanding place through paths and movement, and Munn's theories on generative boundary-making. Through this I hope to destabilize the concept of "home" and material objects, to account more for porosity and leakage in relation to forces of stability, and thereby to generate more possibilities for place and habitability in the world.

Latour's project, in part (2004, 2005a, 2005b, 2009, 2011), is to help establish how non-humans, as co-creators of place, also have a standing in this world. Space, for Latour (2009: 142), is one of many connections made by subjects and things, enacted as "entities trudge along." This approach grants agency to non-humans if they produce traces, participating in actions that transform and modify situations. 
McCracken's (1988) account of the rippling effects generated by the arrival of a fancy dressing gown in Diderot's life is an example of such a tracing. Latour calls these agents "mediators," following the contours and associations that permit the means and processes for assembling and stabilizing patterns. This assemblage of human and non-human actors, traces, and networks Latour (2011) terms "compositions." These compositions generate more space, "where conditions for deployment of life forms is fully provided" (Latour 2009: 143). Tim Ingold (2012) goes a step further, arguing for destabilizing the "object" concept in favor of "materials." In materials we can see histories and on-going processes that are interactive rather than stable, passive objects; as such materials inevitably "leak" (Ingold 2012). From this premise, we can extend agentic interactions to animate non-humans as well. Insects and other invertebrates, bacteria, rodents, a variety of plant materials and other animate forces also engage the process of place-making in the home.

So how is place created? Numerous theorists and philosophers, ranging from Edward Casey (1996) to de Certeau (1984) and many others, have engaged this issue. One theme often running through these explorations is that places co-create with the humans and non-humans who move through them. These co-created places are always in flux. Humans like to move, taking with them memories of previous spaces, their movements always interacting with the moorings and infrastructure in the environment (Salter 2013; Fallov, Jorgensen and Knudsen 2013). In his exploration of nineteenth century Paris arcades, Walter Benjamin (1999) describes a porosity of space-time, and an interpenetration of the past and future with space and the present. Benjamin sees people as always dedicating themselves to creating interiors, while at the same time being always on the move. These interiors, as reservoirs of memories and feelings, work to at least partially immunize existence by constructing protective islands.

Peter Sloterdijk also engages with this idea of immunization in his spheres theory (2009). He argues that people generate atmosphere (which he calls "foam") by mutually exerting pressure, through speaking and building in strong relationships. According to Sloterdijk, this usually creates enough security to enable sphere-like immune structures with reciprocal sheltering (Morin 2009), with implications for designing more habitable spaces in a highly permeable society. This foam concept is useful in demonstrating the generative processes at work in residing, although it also tends to overemphasize stability and can create a sense of restriction that doesn't account adequately for porosity and circulation. As Morin (2009: 69) suggests, we need to engage with praxis in the generation of habitable places.

Setha Low (2003: 10) has also addressed this need to engage praxis in the "intersection and interpenetration of body, space, and culture." Describing the idea of embodied spaces, Low argues that bodies in spaces 
contract and expand in relation to their emotions and experience of self, social relationships, and cultural affiliations. And this intersectionality of bodies and spaces includes the pressures exerted by material objects. Bohme (1993), for example, argues that meaningful home materials also create tensions and suggestions of movement.

\section{Paths}

Given this world in flux, it follows that life is lived on paths as well as in places. Feelings of belonging are produced and reproduced as well along paths of everyday practices: what John Urry (2007) terms the places "inbetween." Homes are porous, and the paths that traverse houses are extensions and transformations of lines that connect to other places, to yards, fields, and woods, to other homes and towns. Walking is one way of knowing, and we generate knowledge of our surroundings in the course of moving through them (Ingold 2004, Ingold and Vergunst 2008). Every path is also gestural, tracing movement and signifying boundaries, and responding to multiple agentive forces. These paths, lines, and gestures necessarily contain an element of uncertainty and risk, as the rhythms of walking take their lead from the environment, answering to conditions of the task as it unfolds (Lefebvre 1991).

As Ingold (2007) describes, these paths are lines of connection, and include walking, cooking, crafting, observing, singing, storytelling, writing, and other practices of line-making. These paths of continuity counter the modernist tendency to map and to fragment lines into a succession of dots and static connectors. With homes as paths and traces created by gestures and agentic actions, inhabitants generatively participate in laying a trail of life, creating knowledge through movement.

\section{Thresholds}

Paths implicate thresholds, and vice-versa. In business-related ethnographic research, we often pay little attention to thresholds. We are obviously aware of entering or exiting a home, but we often don't take the time to contextualize the experience. Viewing homes as places on a path, thresholds are transitional spaces, opening to and (temporarily) closing off paths leading to the home from the street, yards, and from other homes. They are mediators of transitional, often ritualized experience (van Gennep 1960), enacting symbolic boundaries (Jager 2009), midway between staying at home and making a journey; as such they are frequently of liminal or ceremonial importance (Casey, 1996). Benjamin (1999) refers to "threshold magic," the everyday ritual transformations that occur covertly in homes in relation to doorway materials and textures, the nexus of emotions and socialities that are at play with each coming and going. 
These transitional nodes-windows, doors, facades, garages (Hirschman, Ruvio and Belk 2012)-implicate social interactions, intimacy, isolation, inclusion and exclusion (Attfield 2000: 178). The ways in which these thresholds are imagined and enacted differ according to these paths to and fro, cultural and personal preferences, as well as available resources and structural designs. As important mediators of the home, thresholds are loci of emotion and activity. The personalization of thresholds - upgradings, DIY projects, landscaping, and more-are signifiers of identity and aspiration (Attfield 2000). They reflect personal priorities along with ecological relationships. Many embody conflicting motives and resources.

Thresholds are intricately connected to the social landscape, embodying linkages and limits that separate and bind. According to Sarah Pink (2004), for example, in England entrance areas are more for transitions in and out, whereas in Spain they tend to be more decorative spaces. Implicated in these choices are neighborly relationships as well as rhythms of coming and going, the spatial-temporal order, and the interstices and transformations of self.

Even more so than many other areas of the home, thresholds and adjoining spaces are visited by a wide variety of non-human agents from outside the home. Sand, dirt, leaves, sticks, rocks, insects and many other invertebrates, regularly come in attached to shoes, in children's hands, blown in by breezes, or fly or crawl in under their own power. Many times they hitch a ride on the invited non-human agents, such as pets, wood for the fireplace, groceries, newspapers, and flowers, berries and mushrooms from the yard. Many times they leave their own traces, including processes of decay. These uninvited and often unwanted agents interact with humans, inspiring feelings ranging from interest to disgust to resignation. They often create rippling flows, inspiring human actions such as cleaning and other threshold management activities, home improvement projects, and social interactions. Many of them also move out through thresholds, either through their own actions or carried out of the home after use or cleaning, demonstrating repeatedly that homes are inescapably porous.

\section{Situating the study}

To explore these themes I will focus on two inter-related aspects of my research: the home identity project and the production of "excluded spaces." Both of these result from movement and the co-creation of place, from the circulation of not only people but a host of other animate and inanimate agents that also interact with the home in transformative ways impelling human action. This research was done with people who live in a small town, in a rural area, and in two urban centers in the Midwestern U.S. In one case I interviewed a husband and wife together, in one case a single man, and the rest were women (some single, some married). All but 
one owned their homes, and the other was renting his condo. Most participants were interviewed on two separate occasions over a period of months, while two were interviewed only once.

Talk about homes is influenced by both tacit knowledge and reflexive practice (Keane 1997). People draw on the symbolic resources available to them in their representations, and the relationship between discourse and action has to be explored. Language and its performance can generate porosity or act as a fortress resisting it. To explore this relationship, and the knowledge generated through movement and gestural sequences, with each participant we also walked through the house and experienced their various sensory traces (Pink 2004). These textures of sensory experience reflect what Bachelard terms the poetics of place. For Bachelard (1964: 5) it is "the attachments of inhabiting," where the house is a "community of memory and image," of dreams, which becomes a force for integration and continuity. We physically inscribe home places through "organic habits" (Bachelard 1964: 14), though the home also inscribes on us. Walking and touching the textured surfaces of the home is a sensuous and embodied practice (Taussig 1992: 141). This everyday tactility of knowing, through walking and other means of line-making, creates enduring marks and a range of socialities (Ingold 2007).

\section{Identity projects}

Practices of mobility and motility (potential for movement), often encompassing ambivalences, are co-producers of identity (Fallov, Jorgensen and Knudsen 2013). Blunt and Dowling (2006) see homes as porous intersections of social relations and emotions, where multiple identities of gender, ethnicity, class, age, and so forth are reproduced and contested. Homes are invested, emotionally and materially, with ideals of the self, family, and aspects of community. They are infused with both aesthetic and moral narratives reflecting cultural priorities, conflicts, and ambivalences, a bricolage process enacted in material practice (Attfield 2000). They are also narrated through consumption practices (Reimer and Leslie 2004). To illustrate some of these myriad home identity processes, I will turn to some examples from my research. Linda, for instance, who is married and has one son, tries to connect her yard to her house. She says she wants guests to feel welcome as they pass the front threshold. So in the front she plants flowers to soften the presentation of the home to the street. She has transplanted ferns and lilies of the valley from adjacent woods to the front garden. She has also arranged her living room so she can see from the front door out to the backyard, creating a line connecting front to back and to paths on both sides. Meanwhile, in her backyard Linda wants a more natural look, leaving part of the yard in the back of the property as a "nature zone" with a diversity of trees and forest plants. In this area she and her son like to walk, and he and a friend 
dig for bugs in the compost pile. She likes this wilder part of the yard where she and her son can pick berries, mushrooms, or walnuts, and see squirrels, deer, or turkeys. Interestingly, Linda says other adults generally do not visit these parts of the backyard; at parties the adults usually stay on the porch, despite the recent addition of back stairs down to the yard. Linda complains mildly about her son bringing dirt and bugs into the house from the back yard, but she has deliberately kept this part of the yard wild so her son can explore and experience nature.

We can see in these physical and emotional places several zones, with their socio-moral implications, in her yard. Each of these zones is generated, renewed, and sometimes transformed through the movements of people and other agents. The back half is considered "natural", and is "not for everyone." It remains a place in which nature retains a toehold, and is a space of intimacy for Linda and her son to share experiences. There is also a grassy area in the back acting as a transition zone between this more wild area and the home. Then there are the flowerbeds, which she renews every year with new flowers, the back porch and house, with increasing levels of human activity.

For Jennifer, a single woman, paths in and out of her home are explicitly social. She loves to entertain, and friends and neighbors frequently visit. Her kitchen "command center" also connects her at other times to the broader neighborhood and community. It looks outward toward the front street, where she can see people coming to visit or just passing by. Important thresholds exist within the home as well, providing transitional experiences as people move from one room to another. Jennifer appreciates the curved doorways between rooms in her home, which she feels enable the flow of people and activity, and add a sense of comfort and welcome that she aspires to create.

For Kathy and Jack, a married couple, the addition of a three season porch enables different affective and social stories. Jack uses it for "critical music listening," and Kathy's face lights up as she describes what it means to her:

"It's our pride and joy. When I go in that room I feel a sense of lightness, I feel relaxed, and can leave the week behind...I have book club in there, we have movie nights. I like the carpeting and windows, it has a cottage feel."

We can see in these various lines of connection and movement the contours of identity projects as produced through the home. Places such as the home can be viewed as a collection of stories "so far" (Massey 2005: 130). As such, they are encounters, processes, both locutionary and generative. These narratives affect everything, including the arrangement of furniture, the display of aesthetic materials, home improvement projects, and home metaphors. Linda, for instance, describes her home's character as "a fairy tale house on the outside," and as "my Hansel and Gretel house in the woods." Such a representation may seem a superficial 
and sentimental attempt to freeze time into an idealized space. But if we consider the material practices - the backyard zones and paths, and the efforts and care she takes to create particular stories and feelings-such imaginings can also represent a personalized enchantment of place. The trope of the fairy tale then takes on a different dimension, representing a story of longing, a reverie of attachment to place (Bachelard 1964). These ideals are inevitably compromised by realities of time, money, and a variety of competing forces (Miller 2001), reflecting the flux and leakages of being and materials. As a result, homes are constantly reimagined, providing only the illusion of stability. Attfield (2000: 150) characterizes the personal management of space as an impulse to reintegrate the fragments and clutter within the "wild dimension" of living, to generate a sense of renewal in the presence of entropy.

Sarah Pink (2004) argues that sensory experience, or "what it feels like," is a crucial aspect of understanding the experience of home, and that this feeling is a moral story. Kathy explains how it was she and her husband Jack first experienced their home:

"I think I can speak for Jack that it was love at first sight for him, but for me it wasn't. It was owned by someone whose taste was very different from ours'. It felt like more of a museum look. There was like a stiff gray mohair couch right here in the living room. The color scheme in the house was very dark, it had just sort of a high Victorian, cluttered, dark look to it."

While the practices of modernity have privileged the visual above other senses, Pink reminds us of the importance of smell, hearing, touch, and taste in cultural context as well in the generation of the home environment. Kathy's description of her first experience of the house highlights the importance of tactility and other ways of knowing in the sense of comfort and appeal. This felt sense, along with various smells and sounds, may repel or attract us. They may cause us to clean places, to close or open doors, to move toward or away, or to create or destroy. Place impresses upon us through the senses, in turn interpreted through cultural knowledge (Pink 2004: 131). In Kathy and Jack's home, they are engaging in ongoing possession rituals of transformation-from "museum look" to their own tastes, through home improvement and redecorating projects-to create meaningful markers of identity (McCracken 1988).

Places of the home are, of course, intertwined with gender practices and vary across cultures (Sobh and Belk 2011). Perhaps foremost among these is the kitchen, for many people one of the home spaces that is an identity-generator. For Sarah, a married woman living in an older home, the love of the smell of onions and garlic supports her attempts to cook from scratch for her family. Kathy bemoans the sand that comes in on shoes from the backyard and grinds her kitchen floor down, yet for her 
this room is the "biggest quality of life enhancer." For her husband Jack it is "depressing," as what he sees are the mid-1960s' cabinets ("junkers"). Kathy described her feelings about her kitchen this way:

"I cook a lot; it's where we often socialize. It's what truly sold me on the house. It's large, and there's a very large island where people can sit and eat, and where we take virtually all of our meals. And when entertaining family and friends if it's a small enough group we'll be in there. So it would be great if we could redo the kitchen-it was probably redone on the cheap in the early 1990s or late '80s."

For Jennifer, who enjoys entertaining, we can see the movement of people during social gatherings in relation to the structures of her home. She describes the meaning of her kitchen and the human and material flows this way:

"This (a small adjoining room) is the room I shoo everyone into when they're getting into my way in the kitchen. So what happens is when I have a party I make this, I hate to say it, the 'drink' room... A kitchen with only one entrance is foolish, and that's why it needs another entrance, but again, I don't know what I want. I like curves... I like everything about my kitchen. It's the right size to do cooking in... That's why I bought it, it had this nice big window and it had these nice white cabinets."

She goes on to describe the pleasure and sociality of cooking for her:

"I cook-it's therapy-I love to cook. I'm always looking for new recipes, I try things out. I started to love cooking when I moved into this house... (It's like the) command center. Sometimes I feel like a captain, when I have big dinner parties I'm doing 'all hands on deck', when somebody walks in I know exactly what task they're going to be assigned. So sometimes I do think of it as a command center. Because people always prefer to help than not help. So I always have things ready for them."

Daniel Miller (2001) discusses this mobility and engagement between people and possessions, arguing that these materials work to rewrite selves. Which things achieve prominent status at various times is an interactive process, the visible aesthetics resulting from complex relationships, identities, and resources. Meaningful materials have poetic and symbolic weight, creating spaces of intimacy and memory (Makovicky 2007). Put another way, things have "presence" (Marcoux 2001: 228). They embody the dynamic qualities of aspiration, memory, longing, and desire, suggesting "artifice" rather than "artifact" (Ingold 2012). For Beth, a single woman who travels frequently, one of these 
"thick things" (Latour 2005a: 6) is a large world map occupying prime real estate on her kitchen wall. The map works as a trope for how she aspires to live her life:

"My lifestyle is very hectic, I'm rarely relaxed, but it's planned stress. I choose an active and hectic life. My motto in life is 'never say no.' Life goes by so fast and there are so many people I want to spend time with. I want to see every place in the world."

There is also a performative aspect to the display of things in public spaces of the home. For many luxury goods, their principal use may be rhetorical and social (Appadurai 1986: 38). Items on display can be used transformatively, to generate and maintain important social relationships, and, like Beth's map, to embody and inspire. In her analysis of the living room, Money (2007) argues that things symbolically embody these meaningful social relationships and connections. The living room is a transactional space, somewhere between public and private. In contemporary Midwestern homes, it is often a site of the movement of furniture and decorative objects in relation to changing financial means, upgradings, and shifting emotional attachments. Linda, for instance, buys art at festivals to display in her living room and rotates it according to her mood. And while Sarah often avoids sitting in her living room because she finds the sofas uncomfortable, Linda thinks the soft chairs and hardwood floors in her living room convey the hominess she wants to create.

There is often a sense of moral obligation to display certain things in the living room (Money 2007: 366). These include gifts that symbolize familial obligations, meaningful events, and commemorations. These things generate their own narratives. Linda displays a bowl from Spain obtained while on honeymoon that symbolizes her marriage, and her grandmother's china to commemorate this important relationship. Linda and her family also give prominent place to a table they received after her husband's brother died as a way of preserving memories of him.

\section{Excluded spaces}

These identity projects are in flux, co-creating zones of action and inaction. Thresholds lead not only to comforting and cherished spaces, but also to areas that are excluded for various reasons. Such boundary creations are culturally signified and enacted through movements and gestures. Many homes have zones of exclusion, a heterogeneous category in which spaces are designated as limited or no-go areas, which vary culturally and according to the assemblage of people and materials present. These are often sites of embarrassment, frustration, or conflict among family members, of unfulfilled hopes and dreams, of projects notyet realized, of giving in, at least temporarily, to entropic dirt and clutter. 
They may be haunted, in the sense of embodying intersections of memory, unfinished business, and stories of loss and desire, where the past infuses the present with unsettling presence (Edensor 2008). Movements between the home's more visible spaces and its more invisible ones also implicate remembering and forgetting (KorosecSerfaty 1984).

In her work on how Australian Aborigines create excluded places in their landscape through language and gestures, Nancy Munn (1973; 1996) shows how excluded spaces constrain presence, sometimes transiently, at particular locales, through legal or sociomoral delimitation. Every path in the landscape is constantly created through gestures, tracing a going-out and coming-in (Munn 1973: 214). Zones of closeness to center are mapped onto physical space. They objectify controls and limits, may be defined by the owner's vocal extension, and limit mobility. They can be fixed, relatively enduring markers, or more temporary. Munn describes how boundaries of sacred and non-sacred places emerge through mobility and how they are signified, and through this process become inscribed on cultural bodies. Her work demonstrates how place is generated in the complex historical and material relationship between people and the non-human landscape. This locatedness of mobile actors recalls Henri Lefebvre's (1991) assertion that the field moves with us. Visible signs act as topographical markings, and repeatable boundaries are co-created by moving bodies and the agentive force of places.

Excluded spaces in the home reflect emotional, moral, and practical, often conflictual, decisions about aspiration and functionality. They are relational and positional, often hybrid spaces. Hirschman, Ruvio and Belk (2012) argue that the garage is one such space, where possessions not yet dead, nor still fully alive, are often stored: a re-imagined space haunted by family memories. Kathy and Jack relegate their back stairway between the first and second floors to a marginal status, allowing it to accumulate clutter that is not tolerated in most other places in the house-a situation which creates a feeling of embarrassment (Belk, Seo and Li 2007). Regarding another of their excluded spaces, the "upstairs garage," Kathy and Jack describe it as their unfinished master bedroom on a 20 year plan. For them this space is a nexus of contradictions represented by the metaphor "upstairs garage." Though rationalized that it will be transformed one day, Kathy and Jack also express irritation and a sense of lack of completion, of divergent priorities. There are always higher priorities for time and money, and they also like their current bedroom. Jack says he'd like to move it up on the list, but Kathy notes that he puts his time into trees and music, and she into travel and socializing.

Sarah creates paths of movement through thresholds in her home by alternating outside entrances according to the season. The "winter" entrance includes a "mud room" where boots and skis and other "dirty" items can be kept, and where their dog can be wiped off, in an attempt to 
prevent unwanted inanimate materials from being brought into the home. The "summer" entrance, meanwhile, leads directly into the kitchen. Sarah says all of their rooms are 80 per cent finished, reflecting an ongoing dialogue and concessions regarding space. This includes her two daughters' bedrooms. Sarah doesn't spend much time in her younger daughter's bedroom, except to kiss her goodnight, and "de-sludge" it once a year in June. A different sort of place-making occurs in her older daughter's room. With walls full of painted shoes and a landscape of artwork, her room contests the stated functionality of the rest of the home. Sarah calls it an "art room," a "very messy" room with her daughter's paintings, wall art, painted shoes, and supplies. Sarah says she stays out of it; her daughter can de-sludge it herself.

Excluded spaces of the home often take on a gendered tone as well. Men's emotional, sensory, and intellectual experiences of home are often different than women's (Twitchell 2006). They may be attached to an adventure narrative, culturally and locally reappropriated (Pink 2004: 136). Patrick, a single man who shares a duplex with a female roommate, retains a remnant of meaningful adventure materials that used to play a greater role in his life. Now divorced and under-employed, in his half of the basement (where he doesn't spend a lot of time currently) Patrick displays a guitar, a few record albums and a Corvette poster, nostalgic mementoes of his earlier life.

In Kathy and Jack's home, this narrative and ongoing negotiation occurs with regard to Jack's "music room." The room contains Jack's computer with thousands of songs downloaded to it, a messy desk, jumbles of books, two guitars, a karaoke machine that he enjoys using with his daughter, and assorted other things. Jack happily describes it this way:

"I'm surrounded by my stuff. I can get away with anything I want. I had to fight for it here. Look at that. I've got push pins in the walls here; I've got these cartoonish elements, toys. I mean this is not permitted in the house, and I had to fight for it here. And, that's great, I've got the loud music... This room is for performing (music), for fun and teaching my daughter... It's my laboratory, musically, arborculture, I've got my books nearby... It's more of a room for guys... I could spend eight hours in here."

Kathy grimaces ruefully in listening to this description of the room:

"Where do I start? I try to be compassionate. This is Jack's space... It started out when we bought the house... This was to be his home office. He worked from home for several years. Then there's the fact that it's also a music room; there's a karaoke machine, various guitars, keyboards. Lately he's gotten into stereo components. Um, yeah (shaking her head), the room's feng shui is (Jack interjects 
"perfect") abominable. It's, this is just (grimaces, looks at Jack, hesitates), I guess the symbolism of this room starts with the fact that he took down my favorite light fixture in this house... I need order in my life, this room is just (gestures, her hands moving out and down), yeah... But I love Jack, and I know he feels very comfortable here, and it is representative of many things he holds dear, so I just try and let go. It's not relaxing, a 'mish-mash,' too disordered. I can't work in here. I try to be compassionate. It's Jack's space..."

Other excluded spaces are due to disuse. Among my participants this was often the dining room, which was commonly used only for occasional dinner parties or a place to pay bills. It may also be relegated to a children's homework area, or as a convenient spot to unload belongings when coming in from outside. These gestures make it a special zone of transitional activities.

Jennifer describes her bedroom as a kind of excluded space as well. She says her dog spends more time in this room than she does, and he sleeps on the bed. "I don't feel a part of this room", she says, "and I spend hardly any time here. I never start out on the bed, but sometimes I'll come in at 3 am after being on the couch."

Beth has created an excluded space in her home for her cats. They are allowed only in the laundry room of the basement, and she has created a cat doorway for them to come in and go outside as they want. This containment practice is in part due to the "dirt" cats can generate, as well as to limit the possibility for allergies. Another excluded space is her home office, with its messy piles and unfinished business. Beth says that crossing the threshold into this room produces a feeling of stress. "I am a saver," she says, and being in the room "is like working in the office." Though Beth says every now and then she reorganizes it, the room contains piles of work, photo and travel projects in various states of progress.

\section{Implications}

We think we know our homes. It is comforting to see them as stable and a refuge from the chaos of the "street" and vagaries of the outside world. To see the home as fundamentally unstable and uncertain can be unsettling. Yet the home and its human and non-human inhabitants are in constant movement. As a result, there are always possibilities for surprise or an unexpected encounter. And they continually inscribe their stories "so far." About a year after Sarah told me that her kitchen would probably be the last room to be remodeled, I learned that it had been redone by her husband. And Kathy and Jack's upstairs garage? Jack has recently been working on remodeling it, ten years into the reported twenty year plan. 
"Hey, that's great," Jack told me. "It's way ahead of schedule. Tell Kathy that," he added smiling.

My goal in this article has been to open up a greater exploration of flux and movement as practices of the home, in order to more productively theorize these sites of research. In lived environments such as the home, we constantly re-localize place through lines and gestures, enacting identity, memory, and morality projects. These movements create leakages, as well as longing, comfort, conflict, and sensoryemotional engagement. This mobility as place-making, this porosity of experience and generative interaction with non-human actors and the home itself, destabilizes modernity's narrative of containment (Ingold 2007). It also shows lines of connection in a way that redefines the idea of "home" and "community." Latour's ideas of compositions and co-creation show how the practices of inhabiting the home can create possibilities for stability, while simultaneously being unstable and temporary stops. These ideas implicate a different kind of sociality, one that balances the forces of stability, comfort, anxiety and disorder, while interacting with the flows of an ever-changing cast of entities along the path. This movement and sociality create, as Latour argues, the conditions and stories of placemaking.

What are the implications of this approach for business and design anthropologists? A few of the opportunities that may be generated by such research include: understanding the contexts of threshold experiences and their role in the creation of place and sociality; the creation of lines and paths within and among homes and their relationship to a sense of place and community; determining zones of harmony, conflict, intimacy, exclusion, and ambivalence, and how they shape patterns of use and non-use of various materials; how socialities are enabled or restricted by technologies, structures, memories, and various sensory experiences; the movements of various non-human agents and their effects on home practices; and what kinds of mobility and motility are enabled and which constricted by these various forces at play in the home. In addition, there are many other aspects of flux and cocreation not addressed here that remain to be explored, such as the role of technology and mobile devices on home structures and mobilities.

To design for spaces that will generate greater habitability we need to understand the myriad ways in which materials leak and traces have rippling effects, and the ways in which we continually strive to consciously integrate and make sense of these forces. We need to explore the ways in which we seek to balance flows and movement with those of blockage and stability, and make explicit the connections among people, communities, and the non-human environment. By doing so we will be better able to take up the challenge of creating more livable homes and communities, and a greater sense of place. 


\section{References}

Appadurai, A. 1986. 'Introduction.' In A. Appadurai (ed.), The social life of things: Commodities in cultural perspective. Cambridge, UK: Cambridge University Press.

Attfield, J. 2000. Wild things: The material culture of everyday life. Oxford: Berg.

Bachelard, G. 1964. The poetics of space. London: Orion Press.

Belk, R.W., J. Y. Seo and E. Li 2007. 'Dirty little secret: Home chaos and professional organizers.' Consumption, Markets and Culture 10 (2): 133140.

Benjamin, W. 1999. The arcades project. Cambridge, MA: Harvard University Press.

Blunt, A. and R. Dowling 2006. Home. London and New York: Routledge.

Bohme, G. 1993. 'Atmosphere as the fundamental concept of a new aesthetics.' Thesis Eleven 36: 113-126.

Casey, E. S. 1996. 'How to get from space to place in a fairly short stretch of time.' In S. Feld and K. Basso (eds.), Senses of place, pp. 13-52. Santa Fe, NM: SAR Press.

de Certeau, M. 1984. The practice of everyday life. Berkeley: University of California Press.

Edensor, T. 2008. 'Mundane hauntings: Commuting through the phantasmagoric working-class spaces of Manchester, England.' Cultural Geographies 15: 313-333.

Fallov, M.A., A. Jorgensen and L.B. Knudsen 2013. 'Mobile forms of belonging.' Mobilities 8 (4): 467-486.

Hirschman, E.C., A. Ruvio and R.W. Belk 2012. 'Exploring space and place in marketing research: Excavating the garage.' Marketing Theory 12 (4): 368-389.

Ingold, T. 2012. 'Toward an ecology of materials.' Annual Review of Anthropology 41: 427-442.

Ingold, T. 2007. Lines: A brief history. New York: Routledge.

Ingold, T. 2004. 'Culture on the ground: The world perceived through the feet.' Journal of Material Culture 9 (3): 315-340.

Ingold, T. and J. Vergunst 2008. 'Introduction.' In T. Ingold and J. Vergunst (eds.), Ways of walking, pp. 1-20. Burlington, VT: Ashgate.

Jager, B. 2009. 'Thresholds and inhabitation.' Environmental and Architectural Phenomenology Newsletter, pp. 1-5.

Keane, W. 1997. Signs of recognition. Berkeley: University of California 
Press.

Korosec-Serfaty, P. 1984. 'The home from attic to cellar.' Journal of Environmental Psychology 4: 303-321.

Latour, B. 2011. 'Some experiments in art and politics.' E-flux Journal 23 (March).

Latour, B. 2009. 'Spheres and networks: Two ways to reinterpret globalization.' Harvard Design Magazine 30: 138-144.

Latour, B. 2005a. 'From Realpolitik to Dingpolitik, or how to make things public.' In B. Latour and P. Weibel (eds), Making things public: Atmospheres of democracy, pp. 4-31. Cambridge, MA: MIT Press.

Latour, B. 2005b. Reassembling the social: An introduction to Actor Network Theory. Oxford: Oxford University Press.

Latour, B. 2004 'Whose cosmos, which cosmopolitics?' Common Knowledge 10: 450-462.

Lefebvre, H. 1991. The production of space. Malden, MA: Blackwell.

Low, S. 2003. 'Embodied space (s): Anthropological theories of body, space, and culture.' Space and Culture 6 (1): 9-18.

Mackovicky, N. 2007. 'Closet and cabinet: Clutter as cosmology.' Home Cultures 4 (3): 287-310.

Marcoux, J-S. 2001. 'The refurbishment of memory.' In D. Miller (ed.), Home Possessions: Material culture behind closed doors, pp. 69-86. Oxford: Berg.

Massey, D. 2005. For space. London: Sage.

McCracken, G. 1988. Culture and consumption: New approaches to the symbolic character of consumer goods and activities. Bloomington, IN: Indiana University Press.

Miller, D. 2001. 'Behind closed doors.' In D. Miller (ed), Home possessions: Material culture behind closed doors, pp. 1-19. Oxford: Berg.

Money, A. 2007. 'Material culture and the living room.' Journal of Consumer Culture 7 (3): 355-377.

Morin, M-E. 2009. 'Cohabiting in the globalised world: Peter Sloterdijk's global foams and Bruno Latour's cosmopolitics.' Environment and Planning D: Society and Space 27: 58-72.

Munn, N. 1973. Walbiri iconography: Graphic representation and cultural symbolism in a Central Australian society. Ithaca; Cornell University Press. Munn, N. 1996. 'Excluded spaces: The figure in the Australian Aboriginal landscape.' Critical Inquiry 22 (Spring): 446-465.

Pink, S. 2004. Home truths: Gender, domestic objects and everyday life. Oxford: Berg. 
Reimer, S. and D. Leslie 2004. 'Identity, consumption, and the home.' Home Cultures 1 (2): 187-208.

Salter, M. 2013 'To make move and let stop: Mobility and the assemblage of circulation.' Mobilities 8 (1): 7-19.

Sloterdijk, P. 2009. 'Spheres theory: Talking to myself about the poetics of space.' Harvard Design Magazine 30: 126-137.

Sobh, R. and R.W. Belk 2011. 'Privacy and gendered spaces in Arab Gulf homes.' Home Cultures 8 (3): 317-340.

Taussig, M. 1992. The nervous system. New York: Routledge.

Twitchell, J.B. 2006. Where men hide. New York: Columbia University

Press.

Urry, J. 2007. Mobilities. Cambridge, UK: Polity Press.

Van Gennep, A. 1960. The rites of passage. Chicago: University of Chicago Press.

Kevin Browne, Ph.D. is a cultural anthropologist and the founder and principal of Intersource Research and Consulting, LLC in Wisconsin, USA. His doctoral research was carried out in Central Java, Indonesia, on mental health care, and he continues to do periodic research in Indonesia. Currently he conducts ethnographic business and design anthropological research for a wide range of consumer and health care companies. His research interests include health and illness, identity, rituals, food practices, and collecting. He can be contacted at kobrowne@charter.net. 